\title{
Context facilitation and disruption in word identification
}

\author{
SCOTT W. BROWN and RICHARD A. BLOCK \\ Montana State University, Bozeman, Montana 59717
}

\begin{abstract}
A word-naming task was used to examine effects of presenting lists of categorically related words, some of which contained an unrelated disruptor word. A facilitation effect on reaction time (RT) to name related words asymptoted after only one word, or about $3 \mathrm{sec}$. If the context was disrupted, RT to the disruptor word was lengthened, but the contextual facilitation effect persisted over the disruptor interval. Similar effects were found in conditions in which the disruptor word was preceded by one, three, or six categorically related words. The results were interpreted in terms of spreading-activation models of semantic memory.
\end{abstract}

The nature of the effects of set on the identification of a stimulus has been investigated for several decades. Haber (1966) presented an update of Gibson's (1941) review of the literature on set. He concluded that there was evidence supporting each of two major hypotheses. One proposed that set enhances the perception of the stimulus while a person is viewing it, and the other said that set facilitates the response to a stimulus without affecting its perception. The recent use of information processing models and terminology has revived the study of the effects of set, and the focus has shifted from perception to memory. In addition, the term "context" has come to be substituted for set. The kinds of stimuli commonly used are now words or other linguistic units, whereas visually displayed dot patterns were primarily used in earlier studies.

Many recent experiments have shown that an appropriate semantic context facilitates recognition and identification of linguistic units. The basic effect was first demonstrated by Miller, Heise, and Lichten (1951). They reported that words presented with interfering noise could be identified more accurately when they were embedded in the context of a grammatical sentence than in the context of an ungrammatical pseudosentence. Studies of effects of the number of alternatives on the identification of a stimulus have indicated that as the categorical membership of a stimulus is more clearly defined, the probability of correct identification of the stimulus increases (e.g., Reid, Henneman, \& Long, 1960).

In a typical task used to study effects of context, a context word is presented and followed by another word that is either related or unrelated to the first word along some dimension, usually semantic. The choice of a dependent variable differs across studies, but typically a speeded response is required, and reaction time (RT) to the second word is measured. The RT required to

Scott W. Brown is now at Syracuse University. Reprint requests should be sent to Richard A. Block, Department of Psychology, Montana State University, Bozeman, Montana 59717. make either a lexical (word-nonword) decision or a naming response is typically shorter if the second word is semantically related to the first than if it is not (e.g., Meyer, Schvaneveldt, \& Ruddy, 1975).

Warren (1972) used a modified Stroop (1935) colornaming task, and he found greater interference on the task if the critical word was the category name for a set of words being held in memory than if the critical word was unrelated to the set. Warren interpreted his findings in terms of a spreading of activation within semantic memory structures proposed in the logogen model of Morton (1969) and further elaborated by Collins and Loftus (1975) and Posner and Snyder (1975). This model postulates the existence of logogens: memory structures or nodes containing information stored in semantic memory. Logagens that are related on some dimension are located in close proximity to each other. When a logogen is activated through some process of retrieval, activation automatically spreads to related logogens. Warren $(1974,1977)$ reported evidence consistent with these general notions: Interference is found in a Stroop task and facilitation in a word-naming task if the critical word is associatively related to previously activated words.

The present study used a word-naming task to investigate effects of repeated accessing of information from one semantic category on the RT necessary for word identification and naming. As activation is increased in logogens representing instances of a particular semantic category, the identification of a word that belongs to the same semantic category should be facilitated, but the identification of a word from an unrelated category may be inhibited.

\section{METHOD}

\section{Materials and Design}

A total of 26,2 practice and 24 experimental, categorized lists of words were used. Each list contained 7 nouns selected from the 15 most frequently mentioned instances of each of 26 categories used in the Battig and Montague (1969) norms. 
The overall mean rank of the words was 5.33. The particular words used in the 24 experimental lists were selected so that one of the words in each category was graphemically similar to a word in another category. For example, the word "bear" from the "four-footed animal" category is similar to the word "beer" from the "alcoholic beverage" category. Each of these words, which are referred to hereafter as disruptor words, appeared in one of four locations in the presented lists-either in its own category list (control condition) or in the second (Dis-2 condition), fourth (Dis-4 condition), or seventh (Dis-7 condition) position in the category list with which the word was paired. For example, one list was "cow, tiger, dog, beer, horse, cat, lion," and the paired list was "wine, vodka, brandy, bear, rum, whiskey, gin"; the disruptor word appears in the fourth position in both lists. Thus, there were six lists in each of four conditions: control, Dis-2, Dis-4, and Dis-7. Except for the disruptor word, the order of the words in each list was random. Each word was typed in lowercase letters on lightweight paper, which was then mounted in a slide frame. In addition, each list was preceded by a warning slide, which contained a row of five asterisks, and followed by a blank slide. Slides were arranged in four slide trays.

\section{Subjects}

A total of 20 students from an introductory psychology class participated individually in the experiment, which took about $30 \mathrm{~min}$. Each received class credit for participating. Disruptor words were rotated through the four experimental conditions across groups of five subjects. In addition, the order of presentation of lists from the four conditions, which was block-randomized, was rotated after each group of five subjects was run.

\section{Apparatus and Procedure}

Upon arriving for the experiment, the subject was seated in a chair approximately $1.2 \mathrm{~m}$ from a rear-projection screen. A slide projector equipped with a tachistoscopic shutter was aligned so that each slide appeared in the center of the screen. A timer was used to control the presentation of the lists. The exposure duration of each word was $.25 \mathrm{sec}$, and the word lists were presented at a $3-\mathrm{sec}$ rate. A microphone was positioned in front of the subject, and his or her word-naming responses were taperecorded. A voice-activated relay was connected to the timer, the microphone, and a digital clock, which was located in an adjacent room. At the onset of the subject's articulation of each presented word, the clock displayed the RT, which was recorded to the nearest $1 \mathrm{msec}$.

The subject was told that lists of words would be presented on the screen, one word at a time. The task was to identify and name each word as quickly, accurately, and clearly as possible. The subject was told that a slide with asterisks would appear as a warning signal before each list and that a blank slide would indicate the end of a list and the start of a 15-sec rest period between lists. Each subject was told not to correct any errors in the word-naming task but merely to continue the task, naming the next word in the list. The experimenter recorded all naming errors. Any condition in which an error in word-naming occurred or in which equipment failure led to incomplete data was repeated at the end of the session. A maximum of three lists was repeated for any subject.

\section{RESULTS AND DISCUSSION}

A word-naming error occurred on $5.2 \%$ of the lists. A total of five, seven, three, and four first-position words were named incorrectly in the control, Dis-2, Dis-4, and Dis-7 conditions, respectively, and six secondposition words were named incorrectly in the Dis-2 condition.
Table 1

Mean Reaction Time (in Milliseconds) for Words from Each Serial Position in Each Condition

\begin{tabular}{lccccccc}
\hline & \multicolumn{7}{c}{ Serial Position } \\
\cline { 2 - 8 } $\begin{array}{c}\text { Condi- } \\
\text { tion }\end{array}$ & 1 & 2 & 3 & 4 & 5 & 6 & 7 \\
\hline Control & 743 & 690 & 689 & 670 & 668 & 672 & 696 \\
Dis-2 & 743 & 744 & 692 & 674 & 677 & 679 & 684 \\
Dis-4 & 767 & 676 & 670 & 764 & 685 & 685 & 664 \\
Dis-7 & 760 & 681 & 668 & 656 & 663 & 681 & 767 \\
\hline
\end{tabular}

Note-RT to disruptor words appears in italics.

The mean RT for correctly identified words from each serial position in each condition is shown in Table 1. The data were first subjected to a repeated-measures analysis of variance. The main effect of serial position was significant $[F(6,114)=19.63, p<.01]$, as was the interaction between serial position and condition $[F(18,342)=8.41, p<.01]$. Planned comparisons were made to clarify the nature of these expected effects. There was a significant linear decrease in RT across the seven serial positions in the control condition $[F(1,19)=$ 6.34, $\mathrm{p}<.05]$. (However, a post hoc comparison revealed no significant linear trend in RT across Positions 2-7 in that condition, F $<1$.) The RT to the disruptor word in each of the three disruptor conditions was compared with the RT to the word in the same position in the control condition. At the disruptor position in the respective conditions, there was a significant increase in RT in the Dis- $2[\mathrm{~F}(1,19)=5.95, \mathrm{p}<.05]$, Dis-4 $[\mathrm{F}(1,19)=14.92, \mathrm{p}<.01]$, and Dis-7 $[\mathrm{F}(1,19)=$ $9.58, \mathrm{p}<.01]$ conditions. However, there was no significant difference in RT to the word following the disruptor word, compared with the word in the same position in the control condition, in Conditions Dis- 2 and Dis -4 $[F(1,19)=.03$ and 2.27 , respectively, both ps $>.05]$. Finally, there was no significant linear trend in RT across disruptor words in Conditions Dis-2, Dis-4, and Dis-7 $(\mathrm{F}<1)$.

The results of this study support earlier research and theorizing on context effects in word identification and naming. A person is faster at identifying and naming a word that is consistent with a given semantic context than a word that is unrelated to the context. Thus, the results are consistent with a class of models similar to Morton's (1969) logogen-activation model. Further, facilitation caused by the spread of activation to logogens related to the established semantic context appears to asymptote after only one context word is presented, or within about $3 \mathrm{sec}$. If the context is disrupted by the presentation of an unrelated word, word-naming RT increases for that word, but contextual facilitation apparently persists over the 3-sec disruptor interval, and the subsequent word is named as rapidly as if no disruptor word had been presented. In terms of spreadingactivation models, it seems that the presence of a contextdisrupting word did not eliminate the previous activation of logogens related to the context. The present 
study does not clarify whether this effect is caused by a persisting automatic spreading-activation process, a conscious strategy or expectancy process, or both (see Neely, 1977). However, the present methodology and results may be important in suggesting or clarifying future investigations of multiple activations across different semantic categories and the resulting effects on word identification and naming.

\section{REFERENCES}

Battig, W. F., \& Montague, W. E. Category norms for verbal items in 56 categories: A replication and extension of the Connecticut category norms. Journal of Experimental Psychology Monograph, 1969, 80(3, Pt. 2).

Collins, A. M., \& Loftus, E. F. A spreading-activation theory of semantic processing. Psychological Review, 1975, 82, 407-423.

Gibson, J. J. A critical review of the concept of set in contemporary experimental psychology. Psychological Bulletin, 1941, 38, 781-817.

Haber, R. N. Nature of the effect of set on perception. Psychological Review, 1966, 73, 335-351.

Meyer, D. E., Schvaneveldt, R. W., \& Ruddy, M. G. Loci of contextual effects on visual word-recognition. In P. M. A. Rabbitt \& S. Dornic (Eds.), Attention and performance $V$. London: Academic Press, 1975.
Miller, G. A., Heise, G. A., \& Lichten, W. The intelligibility of speech as a function of the context of the test materials. Journal of Experimental Psychology, 1951, 41, 329-335.

Morton, J. Interaction of information in word recognition. Psychological Review, 1969, 76, 165-178.

NeELY, J. H. Semantic priming and retrieval from lexical memory: Roles of inhibitionless spreading activation and limited-capacity attention. Journal of Experimental Psychology: General, 1977, 106, 226-254.

Posner, M. I., \& Snyder, C. R. R. Facilitation and inhibition in the processing of signals. In P. M. A. Rabbitt \& S. Dornic (Eds.), Attention and performance V. London: Academic Press, 1975.

Reid, L. S., Henneman, R. H., \& Long, E. R. An experimental analysis of set: The effect of categorical restriction. American Journal of Psychology, 1960, 73, 568-572.

STroop, J. R. Studies of interference in serial verbal reactions. Journal of Experimental Psychology, 1935, 18, 643-662.

WARren, R. E. Stimulus encoding and memory. Journal of Experimental Psychology, 1972, 94, 90-100.

Warren, R. E. Association, directionality, and stimulus encoding. Journal of Experimental Psychology, 1974, 102, 151-158.

WARREN, R. E. Time and the spread of activation in memory. Journal of Experimental Psychology: Human Learning and Memory, 1977, 3, 458-466.

(Received for publication February 12, 1980.) 